\title{
ARTICLE
}

\section{Why Don't More American Indians Become Engineers in South Dakota?}

\author{
Joanita M. Kant, ${ }^{*}$ Wiyaka His Horse Is Thunder, ${ }^{\dagger}$ Suzette R. Burckhard, ${ }^{\ddagger}$ and Richard T. Meyers ${ }^{\S}$ \\ * Civil and Environmental Engineering, South Dakota State University, Joanita.Kant@sdstate.edu \\ † Counseling and Human Resource Development South Dakota State University, \\ Wiyaka.HisHorselsThunder@sdstate.edu \\ ¥ Civil and Environmental Engineering, South Dakota State University, Suzette.Burckhard@sdstate.edu \\ $\S$ College of Arts and Sciences, Tribal Liaison, South Dakota State University, Richard.Meyers@sdstate.edu
}

\begin{abstract}
American Indians are among the most under-represented groups in the engineering profession in the United States. With increasing interest in diversity, educators and engineers seek to understand why. Often overlooked is simply asking enrolled tribal members of prime college age, "Why don't more American Indians become engineers?" and "What would it take to attract more?" In this study, we asked these questions and invited commentary about what is needed to gain more engineers from the perspectives of enrolled tribal members from South Dakota, with some of the most poverty-stricken reservations in the nation. Overall, results indicated that the effects of poverty and the resulting survival mentality among American Indians divert attention from what are understood to be privileged pursuits such as engineering education. The study's findings indicated American Indian interviewees perceived the need for consistent attention to the following issues: 1) amelioration of poverty; 2) better understanding of what engineering is and its tribal relevancy; 3 ) exposure to engineering with an American Indian cultural emphasis in K-12 schools; 4) presence of role-model engineers in their daily lives; 5) encouragement and support from their peers, families, teachers, Elders, and tribal governments to value science, technology, engineering, and mathematics (STEM) education, particularly engineering fields; and (6) the embedded perceptions of math as a barrier to engineering studies.
\end{abstract}

KEYWORDS: Native Americans, engineering education, inclusion, diversity, critical-design ethnography

\section{INTRODUCTION}

As a matter of diversity and social justice, in recent years there has been increasing interest in educational attainment and participation in science, technology, engineering, and math (STEM) fields among American Indians (Aikenhead, 2001; AISES, 2015; Aragon, 2002; Cahalan \& Perna, 2015; Carnevale \& Strohl, 2010; Demmert, 2006; Hansen, 2015; Straits et al., 2002). In this study, we seek insights into the questions, "Why don't more American Indians study engineering and select engineering careers?" and "What would it take to attract more?" specifically among enrolled tribal members who consider South Dakota home.

\section{US Census and American Indians}

The 2010 United States Census (Norris et al., 2012) provides data for the self-identified "American Indian and Alaska Native (AIAN)" population, an official census category, although tribal governments do not necessarily agree with the statistics listed under that category. Of 308.7 million Americans, 5.2 million (1.5 percent) self-identified as AIANs. From 2000 to 2010, the AIAN population increased by 37.5 percent compared to 9.7 percent for the overall US population. 
South Dakota's Pine Ridge Reservation ranks second and Rosebud Reservation ranks seventh for places in the US with the largest numbers of AIANs. South Dakota ranks second in states in the nation in numbers of AIANs with 82,073, of whom 61,582 identify as "Sioux Tribal Grouping" (US Census Bureau, 2013a), descendants of traditional speakers of Lakota, Dakota, or Nakota: Oceti Sakowin (The Great Sioux Nation).

Held back in part by lack of attainment of bachelor's degrees, American Indians are underrepresented in engineering careers in the United States. When compared with the overall US population, a greater percentage of AIANs graduate from high school (including GEDs), have "some college or associate's degrees," and have three years or more of college or graduate school (US Census Bureau, 2013a). In addition, at 4.9 percent in 2011, American Indians are over-represented in US undergraduate engineering program enrollment, based on their status as only 1.5 percent of the US population. Of that 4.9 percent, 78 percent were American Indian men (NSF, 2011). Despite being over-represented in undergraduate engineering program enrollment, American Indians are underrepresented among engineering program graduates. Consequently, since practicing engineers typically need bachelor's degrees or better, American Indians often lack the educational credentials necessary to enter the profession (see Table 1).

Table 1. Overall US AIAN and overall US population comparisons (Source: US Census Bureau, 2013a)

\begin{tabular}{|c|c|c|c|}
\hline 2010 US Census Detail & $\begin{array}{c}\text { AIAN } \\
\text { Population }\end{array}$ & $\begin{array}{l}\text { US Overall } \\
\text { Population }\end{array}$ & Difference \\
\hline High school diploma, includes equivalency & $28.6 \%$ & $27.8 \%$ & +0.8 \\
\hline Some college or associate's degree & $36.0 \%$ & $29.2 \%$ & +6.8 \\
\hline $\begin{array}{l}\text { Females [having] "3 years and over enrolled in college or } \\
\text { graduate school" }\end{array}$ & $31.1 \%$ & $26.3 \%$ & +4.8 \\
\hline $\begin{array}{l}\text { Males [having] "3 years and over enrolled in college or } \\
\text { graduate school" }\end{array}$ & $25.4 \%$ & $19.5 \%$ & +5.9 \\
\hline Bachelor's degree & $11.6 \%$ & $18.4 \%$ & -6.8 \\
\hline Graduate or professional degree & $6.5 \%$ & $11.2 \%$ & -4.7 \\
\hline
\end{tabular}

\section{South Dakota Set Apart}

There is an old saying in Indian country: "When you visit one reservation, you have visited one reservation"-a warning against generalizing across reservations, since tribes are very diverse. With that in mind, we found that South Dakota's reservations are sometimes set apart as places of great need. For example, New York Times op-ed columnist Nicholas Kristof referred to Pine Ridge Reservation in South Dakota as "Poverty's Poster Child," comparing the locale to Haiti in terms of living conditions and describing the place as follows:

This sprawling Pine Ridge Indian Reservation is a Connecticut-sized zone of prairie and poverty, where the have-nots are defined less by the money they lack than by suffocating hopelessness.

In the national number line of inequality, people here represent the "other 1 percent," the bottom of the national heap.

Pine Ridge is a poster child of American poverty and of the failures of the reservation system for American Indians in the West. The latest [US] Census Bureau data show that Shannon County [renamed Oglala Lakota County] here had the lowest per capita income in the entire United States in 2010. Not far behind in that Census Bureau list of poorest counties are several found largely inside other Sioux reservations in South Dakota: Rosebud, Cheyenne River and Crow Creek. (Kristof, 2012) 
The Annie E. Casey Foundation's 2012 Policy Report spotlighted South Dakota by noting in their children's index of well-being, designed to measure "the steepest barriers to success":

The score for American Indian children in South Dakota is the lowest of any group in any state on the index at 185. The range of scores for American Indian children-185 to 631 -is the widest in the index. (Annie E. Casey Foundation, 2012, p. 14)

Another indicator of lack of well-being, suicide among young people, has long been a problem on Pine Ridge Reservation in South Dakota, where the rate may be among the highest in the world (Young, 2008). Most recently, from December 2014 to May 2015, there were nine suicides on Pine Ridge Reservation among the 12 - 24 age group (Bosman, 2015). A former school administrator on Pine Ridge Reservation described the situation in The New York Times:

Ted Hamilton, the superintendent of the Red Cloud Indian School, a Jesuit school on the reservation, says suicide is an issue that schools grapple with constantly.

"To be Lakota in this world is a challenge because they want to maintain their own culture, but they're being told their culture is not successful," Mr. Hamilton said. "Children on Indian reservations," he added, "have extraordinary challenges: the legacy of oppression and forced removals, the lack of jobs and economic opportunity, and the high levels of drug and alcohol use around them." (Bosman, 2015, n.p.)

Despite a reputation for extreme poverty, there are many places of hope on and near South Dakota's reservations. Promoting STEM education and careers contributes to a sense of hope because it encourages self-reliance and nation-building on reservations as sovereign nations within the United States. Some places that specifically promote STEM include Red Cloud School and tribal college Oglala Lakota College on Pine Ridge Reservation, Sinte Gleska University on Rosebud Reservation, and Flandreau Indian School near the Flandreau Santee Sioux Reservation, among others. For example, the US National Science Foundation is currently funding a program to bring engineering education to American Indians in a collaboration known as Oglala Lakota College, South Dakota State University, South Dakota School of Mines and Technology Pre-Engineering Education Collaborative (OSSPEEC) (Boyer, n.d., ca. 2012 and 2015; Kant et al., 2014a and 2014b; Sawyer et al., 2014; Tinant et al., 2014).

Tribally-related schools that promote STEM education are important for reservations in building sovereignty and self-determination. Hannan LaGarry (referenced below as HEL), formerly head of the Science and Math Department at Oglala Lakota College on Pine Ridge Reservation, wrote about the establishment of their pre-engineering program, OSSPEEC, at this tribal college and its relationship to tribal sovereignty:

For the first time, we [Oglala Lakota College] are producing students who can advise the State and Federal governments, and our students are becoming knowledgeable enough to oppose them with evidence-based research, when necessary to maintain tribal sovereignty (HEL).

... Now we [Oglala Lakota College] have people from within and outside the tribe who seek us out for expertise. Now we have people who come to the reservation who want to collaborate with us. We have so many, we cannot manage them all. Now we can pick and choose (HEL). (Tinant et al., 2014, p. 11)

\section{UNDERPINNINGS OF RESEARCH}

The current pilot study has roots in an on-going US National Science Foundation (NSF) funded project seeking to develop the OSSPEEC initiative. In this initiative, starting in 2011, co-authors Kant and Burckhard found that it was challenging to recruit AI pre-engineering students into OSSPEEC. Recently, in collaboration with co-authors Meyers and His Horse Is Thunder, they 
conducted a literature review to answer the questions, "Why don't more American Indians become engineers in South Dakota" and "What would it take to attract more?" That literature review found numerous articles about American Indians in STEM education (Babco, 2005; Chen, 2009; HowardBrown, 2012; National Center for Educational Statistics, 2008 and 2011; Pewewardy, 2002), but none addressed the specific questions of interest. This pilot study was designed to fill that gap in the literature.

The critical pedagogy movement and liberation theology of Paulo Freire, as expressed in his books, Pedagogy of the Oppressed and Education as the Practice of Freedom, provide normative underpinnings for this inquiry. The most powerful element of Freire's work is that liberation pedagogy must be understood and realized at the level of those involved. In this vein, our study and analysis do not simply follow an a priori, top-down, imposed approach. As Freire noted,

No pedagogy which is truly liberating can remain distant from the oppressed by treating them as unfortunates and by presenting for their emulation models from among the oppressors. The oppressed must be their own example in the struggle for their redemption. (Freire, 1970, p. 54)

As a matter of diversity and social justice (Baillie et al., 2012), we asked American Indian student interviewees (referred to here as "AI students") and non-AI student interviewees ("non-AI students") to partner with us and to share their understandings about what has happened in their lives and what should happen in bringing engineering education to them in South Dakota.

\section{METHOD}

\section{Critical-Design Ethnography}

In line with Paulo Freire's insights, we sought meaningful engagement with our research subjects as much as possible, where American Indians were allowed to seek their own answers in their own voices and to serve as their own examples (Freire, 1970). Aside from that emphasis and in terms of contemporary anthropological research design and strategies, our research is exploratory, similar to grounded theory that seeks descriptions that may lead to the evolution of meaningful theory and metrics and that may precede explanatory research (Bernard \& Gravlee, 2014; Hammersley \& Atkinson, 2007).

To pursue this exploratory approach, we conducted critical-design ethnography, where the objective was to determine how to better understand why more AI students do not pursue engineering educational credentials and careers, and how to encourage more to do so. The method is inductive, seeking patterns rather than testing hypotheses. "The process sits at the intersection of participatory action research, critical ethnography, and socially responsive instructional design" (Barab et al., 2004, p. 254). We applied collaborative, critical-design ethnography including semistructured dialogic interviews with structured open-ended and select-a-response questions, resulting in both qualitative and quantitative data (Hammersley \& Atkinson, 2007; Savin-Baden \& Howell Major, 2013).

We engaged staff and students at the American Indian Education and Cultural Center at South Dakota State University (SDSU) to recruit undergraduate AI student interns to conduct interviews, a deliberate strategy that follows suit with participatory action research. In participatory action research the goal of ethnography is to empower and to build relationships with the research community.

This model, in turn, is also critical ethnography because it attempts to engage in social change by way of taking a critical stance, where the researchers (in this case, the AI student interns) become 
the change agents who are collaborating with the community under study. In recruiting AI student interns to conduct the interviews with AI students, we were afforded change agents engaged in collaboratively developing structures intended to critique and support the transformation of the American Indian communities being studied. The roles of the AI student interns were as critical ethnographers and instructional designers. They were interested in research and development of designed structures that may facilitate learning and empowerment, as well as the relationship of a segment of South Dakota's American Indians to engineering.

Interns received a week of training in ethnographic interviewing techniques and research instrument construction (a methods boot camp), which followed a discourse-centered approach (Farnell \& Graham, 2000) conducted by SDSU anthropologist Richard T. Meyers (an enrolled member of the Oglala [Lakota] Sioux Tribe) and SDSU geographer and biologist Joanita M. Kant. Training included self-reflective journaling for AI student interns about being an American Indian in South Dakota, role-playing to test sample probes, and describing cultural norms in their respective communities within focus groups.

Project leaders and all student interns completed two weeks of training. In addition to the methods boot camp for interns, the first week included earning on-line training certificates in Protecting Human Subjects in Research from the National Institutes of Health (NIH, 2015). Interns and some project leaders also met with Norm Braaten, SDSU's Research Compliance Coordinator, for a research ethics question-and-answer session. During the second week, interns participated in training around the question, "What is engineering?" with SDSU Professor of Civil Engineering Suzette R. Burckhard.

None of the AI student interns were engineering majors, since that candidate pool is very small. (Out of about 12,500 students at SDSU, only about 240 self-identify as American Indians, and very few of them major in engineering.) The AI student interns were enrolled tribal members in some of South Dakota's Oceti Sakowin (Great Sioux Nation) tribes: Yankton Sioux, Cheyenne River, Oglala Lakota, and Standing Rock. Their majors included political science, counseling and human resource development, environmental science, interior design, and nursing. In addition, we recruited one non-AI intern, an engineering major, to conduct comparison interviews with non-AI students currently not majoring in engineering.

\section{Research Instrument}

All student interns helped to construct the research instrument that was used to conduct the interviews. All interviewees, both AI and non-AI students, considered South Dakota as "home," and the study only included those of prime college age, from 18 through 30 years, with at least some education beyond high school (even as little as one class), all non-engineering majors. The reasoning for these selection criteria was to include those most likely to be in the post-secondary education system by age, and those who had shown at least some inclination to seek education after high school. We selected non-engineering majors because the topic is not "Why did you major in engineering?"- - a question that is beyond the scope of this study. Rather, the questions we asked sought insights into why certain categories of people do not major in engineering and seek engineering careers, and how to attract more of them to the profession.

About half of the AI students in this study were enrolled in the Oglala [Lakota] Sioux Tribe with ties to the Pine Ridge Reservation, and over 90 percent of AI students in the study were enrolled in tribes comprising the Oceti Sakowin (Great Sioux Nation). Seven percent were enrolled in various non-Oceti Sakowin tribes, which is appropriate because of the large number of non-Oceti Sakowin AIANs in South Dakota. We also interviewed a non-American Indian comparison group. We refer to American Indian interviewees as "American Indian (AI) students," their parents as "AI parents," 
non-American Indian interviewees as "non-AI students," and non-American Indian parents as "nonAI parents."

Having established a research instrument and the population characteristics for their interviewees, student interns used a "snowballing" technique (Bernard, 2014) to identify interview candidates. Snowballing entailed notifying friends and relatives that they were seeking interviewees; those, in turn, contacted others to enlist their participation. Using this technique, AI student interns independently recruited $107 \mathrm{AI}$ students, and the non-AI student intern independently recruited 30 non-AI students. Snowballing has been shown to be effective in gaining participants among the state's tightly knit tribal populations (Kant et al., 2015). From July 18 to September 11, 2015, the interns conducted and transcribed all interviews using the research instrument shown in Figure 1.

Part 1.

1. Age?

2. Gender?

3. Where did you grow up?

4. Where do you consider home?

5. What is your tribal affiliation?

6. What was your experience like in school?

7. What's your highest level of education?

8. What is your parents' highest level of education?

9. What comes to mind when you think of engineering?

10. Have you had any exposure to engineering?

11. What was your experience with engineering?

12. Have you ever considered engineering as a field of study?

13. What might have encouraged you or your friends to study engineering or become an engineer? Prompt: Engineering is the creative application of math and science to solve problems. Examples of engineers include mechanical, civil, electrical, and agricultural, to name a few.

\begin{tabular}{|c|c|c|c|c|c|c|}
\hline 14. & $\begin{array}{l}\text { On a scale of } 1-5 \text { how much influence did the following } \\
\text { have on your field of study? }\end{array}$ & $\stackrel{0}{\frac{0}{0}}$ & $\stackrel{\oplus}{ \pm}$ & 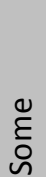 & 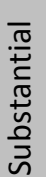 & 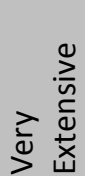 \\
\hline A & Family & 1 & 2 & 3 & 4 & 5 \\
\hline B & School activities/classes & 1 & 2 & 3 & 4 & 5 \\
\hline C & Personal interest & 1 & 2 & 3 & 4 & 5 \\
\hline D & Activities/programs outside of school & 1 & 2 & 3 & 4 & 5 \\
\hline $\mathrm{E}$ & Other if applicable & 1 & 2 & 3 & 4 & 5 \\
\hline
\end{tabular}

Figure 1. Research instrument: Interview questions, Parts 1 and 2

\section{Coding the Data}

After the manner of Strauss \& Corbin (1990), Liamputtong \& Ezzy (2005), Liamputtong (2007), and Dickson-Swift et al. (2007), we formed a plan to code the data. First, co-authors Kant and His Horse Is Thunder coded the interviews by repeatedly reading them to identify persistent themes. Recognizing that some words and phrases applied to more than one theme, they combined some themes while attempting to preserve the intent of the interviewees' comments. Second, they colorcoded words and phrases related to the themes. Third, they extracted percentages or generalizations from the coded data. Fourth, they selected individual quotations from AI student 
interviews representing certain themes to convey deeper insight. Fifth, they contrasted the AI students' responses with those of the non-AI students to provide some basis for comparison.

\section{Limitations of the Study}

The National Center for Educational Studies (2008) has noted that readers should use caution when generalizing about their data relating to American Indian studies for the reasons listed below. In like manner, we caution readers that, as in many larger studies of American Indians, our sample populations are small, reducing reliability of the data. Because of this, even large observed differences may not be statistically significant. In addition, self-identification of tribal affiliation may be unreliable. We provide only a sample of the range of the hundreds of variables that might be extracted from our data. Some comments by interviewees may fit well into more than one theme. The topics of interest represent complex relationships and many interactions that we only briefly explore. In addition, snowball sampling does not provide randomized study populations, but we found that it was the best way to recruit participants in significant numbers among South Dakota's American Indian population with limited resources and funding for the research.

\section{RESULTS AND DISCUSSION}

This section summarizes and discusses the results of our interviews, organized according to our research questions.

\section{Study Population Demographics}

\section{What are your age, gender, hometown, and tribal affiliation? (Questions 1-5)}

Table 2 summarizes results from questions 1 through 5 in the research instrument including age, gender, hometown, and tribal affiliation. Although 76.6 percent of AI students indicated that their hometown is on an American Indian reservation in South Dakota, many others identified hometowns just outside reservation boundaries in South Dakota. Although interviewees reported enrollment in 14 tribes, the largest group, 52 percent, is from the Oglala Lakota Sioux Tribe (i.e., Pine Ridge Reservation), and the majority are from various tribes within the larger category, Oceti Sakowin (Great Sioux Nation). While there are 82,073 persons who identify as AIANs in South Dakota, over 20,000 identify as members of non-Sioux tribal affiliations (US Census Bureau, 2013). Thus, it is appropriate to have included other tribal groupings in our study, although South Dakota is historically thought of as the homelands of the Oceti Sakowin.

Table 2. Study population demographics (American Indian students were enrolled in 14 tribes)

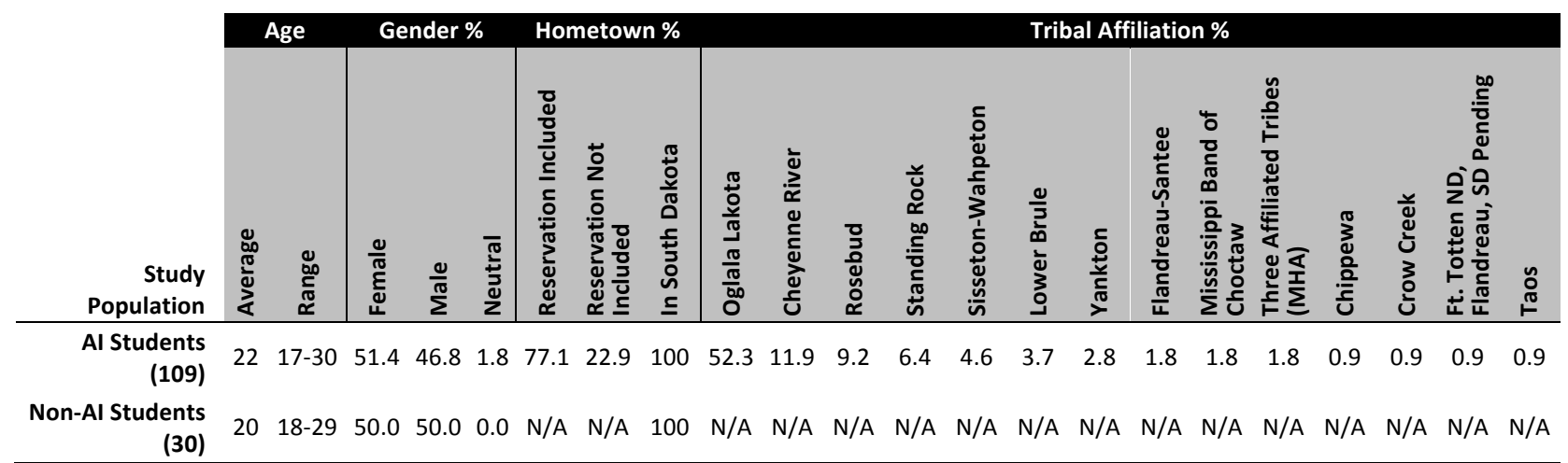




\section{School Experience}

What Was Your Experience Like in School? (Question 6)

The following themes were most commonly reported by AI students regarding their experiences in school, in order of frequency:

1. Likes school, 46 percent

2. Difficulties with school, not academically or socially prepared, 24 percent

3. Negative view of school, 18 percent

4. Apathetic toward school, 17 percent

Sub-themes for school experience report by AI students included the following, in order of frequency (Question 6, continued):

- Poorly performing on-reservation schools and staff compared to off-reservation schools

- Stressful school and home-life

- Frequently moving

- Difficulty transitioning from the reservation to non-reservation

- Teenage angst and bullying

- Lack of encouragement

- Financial difficulties

- Responsibility for relatives

The differences between AI and non-AI students' attitudes toward school are shown in Table 3. In addition, 10 percent of non-AI students (i.e., 3 of 30) reported financial concerns, and three percent (i.e., 1 of 30 ) made negative statements about personal well-being, such as items listed in the subthemes category above.

Table 3. Comparison of AI student and non-AI student school attitudes

\begin{tabular}{rrcccc} 
& & \multicolumn{3}{c}{ Highest Ranking Statements about School Attitudes \% } \\
\cline { 2 - 5 } Study Population & Likes & $\begin{array}{l}\text { Does well } \\
\text { and likes }\end{array}$ & $\begin{array}{c}\text { Negative or } \\
\text { apathetic view }\end{array}$ & $\begin{array}{c}\text { Under-prepared } \\
\text { academically or socially }\end{array}$ \\
\hline Al Students (107) & 46 & - & 17.5 & 24 \\
Non-Al Students (30) & - & 93 & 7 & (but only in high school) & 3 \\
\hline
\end{tabular}

\section{Educational Attainment}

What Is Your and Your Parents' Highest Level of Educational Attainment? (Questions 7 and 8)

Table 4 summarizes results for educational attainment. AI parents occasionally did not graduate from high school, unlike non-AI parents. AI parents were much less likely to hold higher degrees than non-AI parents in every category except associate's degrees. Only 5.5 percent of AI students' fathers held bachelor's degrees, compared to 46.7 percent of non-AI fathers. Fourteen percent of AI students did not know their father's highest level of education or did not respond, which may have artificially reduced their fathers' educational attainment scores. Non-AI students generally knew their parents' highest level of education.

AI students' mothers lagged behind non-AI mothers in educational attainment in every category except associate's degrees. Across the entire study population, STEM majors were rarely reported, with the exception of medically related degrees. 
Table 4. Study population and their parents' educational attainment

\begin{tabular}{rccc|cccccc} 
& \multicolumn{2}{c}{ Years } & STEM & \multicolumn{3}{c}{ Highest Level of Earned Certificates and Degrees \% } \\
\cline { 2 - 9 } Study Population & Average & Range & Major \% & Certificate & Associate & Bachelor & Master & Doctorate \\
\hline Al Students & 14.9 & $12.1-18$ & 2.8 & 1.8 & 7.3 & 5.5 & 1.8 & 0 \\
Al Mothers & 14.4 & $8-21$ & 1.8 & 1.8 & 15.0 & 17.4 & 12.8 & 0.9 \\
Al Fathers & 12.9 & $8-21$ & 3.7 & 1.8 & 5.6 & 5.5 & 2.8 & 1.8 \\
\hline Non-Al Students & 14.0 & $13-16.1$ & 0 & 6.7 & 6.7 & 16.7 & 0 & 0 \\
Non-Al Mothers & 15.3 & $12-18$ & 0 & 13.3 & 6.7 & 30.0 & 20.0 & 3.3 \\
Non-Al Fathers & 14.8 & $12-20$ & 3.3 & 13.3 & 3.3 & 46.7 & 6.7 & 3.3 \\
\hline
\end{tabular}

\section{Experience with Engineering}

\section{What Comes to Mind When You Think of Engineering? (Question 9)}

The most common themes for AI students were, in order of frequency: math, building and creating things, infrastructure and vehicles, and difficulty. Less common themes included: science, designing and inventing, types of engineering, working on things, and problem solving. Types of engineering listed included: mechanical, electrical, chemical, computer, bioengineering, medical, and environmental. Although most did not, one AI student gave a lengthy reply to this question:

[Engineering involves] tanks, trains, bridges, rockets, and those weird metal art shapes in front of public buildings. Anything big that has ever happened to humanity, kind of has to do with engineering-ships and planes, tanks and guns. Anything major that has happened, engineering was in its back pocket.

For the non-AI students, the most common themes were, in order of occurrence: math, building and designing, science, and smart. Less common themes included: blueprints, architecture, and problem solving.

\section{Have You Had Any Exposure to Engineering? (Question 10)}

Forty-eight percent of AI students responded yes, and 52 percent responded no. Non-AI students replied 60 percent yes and 40 percent no. Many of the exposures that both groups identified as engineering were not typically considered to be engineering activities, such as repairing cars. Many of those who responded that they had no exposure to engineering, later reported instances of exposure that they had not recognized to be engineering, such as Gear Up activities, ${ }^{1}$ indicating that many interviewees do not understand what constitutes engineering.

\section{What Was Your Experience with Engineering? (Question 11)}

Among AI-student respondents, two majored in engineering at some point, but one changed majors to music and the other only completed a short course as part of the military with no indication of intent to continue in engineering. AI students reported only one parent as a practicing engineer. The most frequent experience reported was knowing a friend or relative with some connection to engineering, followed by having had a summer experience through Gear-Up, and having participated in an event at SDSMT or Oglala Lakota College or other university. Infrequently listed experiences included American Indian Science and Engineering Society (AISES) events, the Army,

1 Gear Up is a US Department of Education program aimed at increasing enrollment in college and postsecondary educational programs among high-poverty populations. In South Dakota, the state's Gear Up initiative focused specifically on American Indian populations. 
on-line searches, some college courses, and high-school class visitors. It was rare that they reported no experience in response to this question. This disparity is explained in responses to Question 10, above.

One non-AI student reported having a father with an engineering degree, but went on to say that he now teaches high school. Non-AI students most often reported: knowing an engineer or knowing an engineering student, no experience, or having participated in some high-school or middle school activities. Less frequent replies were middle-school engineering camps, high-school competitions, and tours of SDSMT.

\section{Have You Ever Considered Engineering As a Field of Study? (Question 12)}

AI students replied 29 percent yes and 71 percent no. Results were nearly the same for the non-AI students at 30 percent yes and 70 percent no.

\section{What Might Have Encouraged You or Your Friends to Study Engineering? (Question 13)}

AI students reported the following (multiple responses were allowed):

- More information about engineering, 44 percent

- Exposure to engineering, 29 percent

- Want engineering programs, 28 percent

- Want more engineering curriculum and faculty support, 26 percent

- If liked math (i.e., see math as a barrier), 23 percent

- Need to know someone who is an engineer, 13 percent

- Encouragement, 11 percent

- Need for engineering to relate to community, 10 percent

- More confidence in their own capabilities, 7 percent

A few AI students reported exposure to engineering activities in middle and high school that were encouraging, especially through Gear-Up and Oglala Lakota College. Three examples of such comment follow:

I think that all of the cool experiments that were going on in Gear-Up encouraged a lot of the students to go into engineering. It was usually the males who were more excited about it. For me, I really enjoyed the chemical experiments. Those were pretty cool. I think that an afterschool program that is a continual thing would help get males and females interested in it. Have an hour or two hour engineering program where you have the experiments, challenges, or contests to get people interested in it.

One time we had a blacksmithing class where we made our own things out of metal, we used the heat to bend the metal. In another class, each of us had a group where we participated in college students' engineering assignments.... We helped the student with that. College students would also come in and present their experiments (robots, dry ice, and chemical reactions).

There was a science program at Little Wound where we would go to the Oglala Lakota College (OLC) and play with flight simulators. We would get into groups and build our own type of aircraft and would have to do it with under one million dollars. If it couldn't get from point A to point B then we would have to start over. I thought it was pretty cool.

Among AI students, one of the most pervasive comments was that they had a general lack of understanding of what is involved in becoming an engineer. For example, some AI students noted:

$[\mathrm{N}]$ ever have I ever given it a thought. It was never really an option in high school. I mean, you never did hear anyone talk about why we should go into engineering. 
I don't even know what they [engineers] do; so I would never just decide one day that I want to be an engineer.

No, I have never considered it because I have no idea what it is or what engineers do.

Generally, AI students reported that there is a need for consistent exposure to engineering studies and careers beginning as early as grade school and continuing through high school. Other engineering exposures listed include after-school programs, summer programs, workshops, and camps, as well as internships and apprenticeships at tribal colleges. AI students noted the importance of high-school engineering classes, renewed focus on math courses (especially those necessary for engineers), caring mentors and advisors, and extraordinary teachers.

AI students also recommend consistently presenting to K-12 students details about "the system": types of engineering, engineering salaries, what engineers do on a daily basis, descriptions of highschool and college courses required to earn an engineering degree, how much education is necessary to become an engineer, how the college culture operates, and how engineering education might be funded. One AI student responded as follows.

Give students more information about it and about the opportunities. I would get graduates, who have a job in engineering to come in and express their experiences, whether they are native or non-native.... Students could get every little detail from dorm life to academics, summers, and how to pay for it. Let students know that there are different ways to accomplish those things, but how they persevered, without race being a part of it.

AI students reported the need for encouragement that they can achieve their educational goals, and the necessity of a strong work ethic. They indicated that educators should provide role models in reservation settings. They emphasized that information should be tailored to the individual student and related to helping a reservation community. Persistent themes include a desire to help others, especially their reservation communities through culturally relevant, creative, and interesting activities. AI students reported the need to understand the effects of engineering in various aspects of daily life.

AI students acknowledged the importance of financial support from tribal governments. They also recommended the inclusion of families in engineering-awareness-raising activities, since many students are "non-traditional" and some college students have infants and young children. They indicated the need to include parents, grandparents, teachers, Elders, and tribal governments, since their encouragement may be vital in making engineering education meaningful to American Indian community interests.

\section{Reflections on the Role of Poverty and Traditional Culture}

One important finding of this study is that AI students consistently reported that they failed to see how engineering could help reservation communities. The following are insightful comments from AI students, many of whom are caught up in poverty intertwined with their traditional culture. Their comments invite new interpretations of this century's revived concept of the "culture of poverty" (Small et al., 2010). Far from blaming those in poverty for their situation, our findings here indicate that poverty and its resulting survival mentality divert attention from what are understood to be privileged pursuits, such as engineering education. Consideration of these comments helps to explain why, considering Maslow's (1943) hierarchy of needs, becoming an engineer may not be a priority for many American Indians in South Dakota. 
As with the rest of this study, AI student comments assert the importance of consistency in addressing barriers to engineering. AI students identified the following needs:

1) Amelioration of poverty

2) Understanding of what engineering is and its tribal relevancy

3) Exposure to engineering with cultural emphasis in K-12 schools

4) Presence of role-model engineers in their daily lives

5) Encouragement and support from their peers, families, teachers, Elders, and tribal governments to value STEM education, particularly engineering fields

6) Attention to embedded perceptions of math as barriers to engineering studies

Examples of barriers in the wake of poverty include these three comments by AI students:

Growing up in poverty you aren't expected to grow or further your education.

There aren't enough people talking about ways to pay for school.

I feel like the kids don't have the confidence to do it. They think, "Oh, I'm just going to go to tribal college because I can't make it out there financially." Let them know that they can do it, but that they will have to make that decision on their own.

While it is not typical to have both parents die young on South Dakota's reservations, one 21-yearold interviewee reported:

Right now, I am at [a tribal college] after being at [an out-of-state college] for two years.... I like my classes... The reason I came back was because my mom died ... then my dad followed. I was left with my little sister and brother to look after. My parents were really proud of me when I went to college. We never had much money because they didn't go to school and get good jobs like some people's parents, but they did their best.

Examples of the need for understanding the tribal relevancy of engineering and other cultural gaps include these three comments by AI students:

Maybe if we weren't in so much hurt we would have time for important things like engineering. But you can't blame us for wanting to fix all the issues we face now.

A lot of people want to change the reservation so badly; so they do the things that would change it all. Do science and engineering have the ability to turn around the reservation as fast as a business or economics degrees? Everyone is living to survive and what that means is that a job is money, and a degree is one that will ease the poverty. That means people want to be nurses, politicians, and psychologists. So why would people worry about engineering?

It's pretty much a lack of representation of our ethnicity. One of my friends is pursuing a degree in engineering, but he does a lot for the Native American community in Rapid City. He's working with the Rapid City Police Department and Congress, and it has opened a lot of doors for him. It helps a lot seeing one of our own doing something in a specific field. If there were more people who did that around me [it would help in recruiting more native engineers]. Not a lot of people in my family are engineers. They are in construction and child care.

Aside from the cultural relevancy just described, AI students noted the need for exposure to engineering in elementary through high schools, as in these four comments:

It all starts with middle school and high school when the teachers start asking students what they want to pursue in life. Most kids say a doctor or lawyer. Giving them the idea of doing something other than that, in order to influence them in the science classes would help. There could be a curriculum that incorporates engineering as well.

Start young. Start encouraging kids in the eighth grade level because most kids go into high school not knowing what they want to be when they grow up.... If you show them that they 
can do something that they can be proud of, then maybe you can get more Native American students in the field of engineering.

All my friends are in college in everything but engineering... But it would have to take a lot to change their minds to become an engineer, let alone encourage them. It would have to start when we were freshmen in high school for us to be encouraged.

I think if we all knew that we could do it and have had the support to guide us along the way, it would have been possible [to become engineers]. At ... [a reservation high school] they help you apply for college and get accepted, then kick you out the door and tell everyone that they have a 100 percent graduation rate and that all the graduates have plans for higher education. Then that's it. No one wants to go the full way with people. Our parents would, but even they don't know what engineering is or what it entails. So I would say the mentoring, that's always important.

AI students also provided examples of the importance of having role-model engineers in their daily lives, as in these four comments:

In high school I took a lot of automotive courses and there were 23 guys in the class and maybe three girls. Promote the idea that it is okay to be interested in that kind of stuff, that it isn't bizarre for girls to be interested.

When I was in school, engineering was one of my top choices, especially in grade school. I was always told I could be an engineer, but as I got older my mind changed. I didn't know a lot of engineers when I was growing up. I was more around my family being in the hospital, so instead of being an engineer, I thought I would be something else.

A huge part of it is that we don't have a lot of engineers on the reservation. There are only a few of them and most of the stuff that we have done here [on the reservation] is done by independent contractors outside of the reservation.

In addition, AI students spoke of the need for encouragement from peers, families, teachers, Elders, and tribal governments in promoting STEM education, particularly engineering:

I don't think a lot of my friends know about engineering. It would have taken a lot of work to get them to do engineering because it took a lot for them to even go to college. Most are back home now or going to OLC [Oglala Lakota College]. If there was some kind of support system that involved family, friends, and schools to make people do these things, I think it would make a big impact.

Where we're from, the dropout rates are extremely high; so it doesn't really cross minds to study engineering. The teachers know we drop out, so they aren't as willing to teach us. If maybe we had better teachers who actually stayed longer than two years, they could make a difference in students' lives.

Finally, AI students spoke of math as a barrier to engineering studies in comments such as these four:

In high school, they didn't offer calculus or pre-calculus, so that hindered my experience here and discouraged me from majoring in a STEM field, because most STEM fields require something beyond Calculus II. I think that if high schools offered better math classes or prep classes for college that it would encourage more students to major in engineering.

Through high school, you got pushed through just to graduate. You didn't really get the education you should have had or that you deserved from tribal schools. I feel like I didn't get the education I needed to pursue the field that I am in now. I had to learn math and stuff like that on my own time during the summer in order to excel in college level academics.

I wanted to design things when I was younger, but when my math abilities hit a wall I had to pursue something that didn't involve so much math. I was putting myself through college, and I couldn't afford to retake a math class. Math books are expensive, and also it required a 
lot of time, and I was working 40 hours a week. If I had more financial help as a student, then I probably would have gone in that direction.

Some students might not be attracted to it [engineering] because they don't feel confident in math or science. From what I'm familiar with, math was a big obstacle for a lot of students, and science wasn't a very well-studied subject in school either. Math and science were based off college readiness tests. I didn't have that many problems with math and science in high school, but math was really heavily complained about, and there weren't a lot of classes for science.

Non-AI Student Comparison: What Might Have Encouraged You or Your Friends to Study Engineering? (Question 13)

Non-AI students reported the following in response to Question 13:

- Need more family or friends in engineering, 37 percent

- More information, 37 percent

- Encouragement, 33 percent

- Need to like math, 30 percent

- Money reward or pay incentives, 23 percent

- Need to be smart/genius, 20 percent

Overall, non-AI students generally reported the following, all of which is consistent with AI students' reporting:

- Engineering is not seen as a helping profession concerned about people and incorporating idealistic goals, attributes that students seek in careers.

- Engineering studies might be of more interest if students had more relatives and friends in that field.

- Students need more information about engineering in high school and more encouragement to study engineering.

- Inadequate preparation in math is a barrier.

Factors Influencing Selection of Major (Question 14)

Table 5 summarizes rankings of factors identified as influential in selecting post-secondary majors for AI students and non-AI students. Personal interest ranked highest, averaging between "substantial" and "very extensive" influence. Family, school activities, and outside school all scored with an average near "some" influence. Overall, when comparing the two groups, there were no statistically significant differences.

Table 5. Influence of factors in selecting post-secondary majors

\begin{tabular}{rcccc} 
& \multicolumn{4}{c}{ Average Score } \\
\cline { 2 - 5 } Study Population & Family & School Activities & Personal Interest & Outside School \\
\hline Al Students & 3.3 & 3.0 & 4.5 & 3.0 \\
Non-Al Students & 3.0 & 3.8 & 4.7 & 3.1 \\
\hline
\end{tabular}

Note: Rankings of factors: 1 =none; $2=$ little; $3=$ some; $4=$ substantial; $5=$ =very extensive

\section{CONCLUSION}

We analyzed interviews from 107 American Indian students (AI students) and a comparison group of 30 non-American Indian students (non-AI students) of prime college age, all currently nonengineering majors, all of whom consider South Dakota as their home state. Student interns 
conducted standardized interviews to seek insight into the questions: "Why don't more American Indians study engineering and select engineering careers in South Dakota?" and "What would it take to attract more?" The main finding of this study is that the effects of poverty and the resulting survival mentality divert attention from what are perceived to be privileged pursuits such as engineering education.

In contrast to the non-AI students, AI students' parents had a much lower achievement rate of bachelor's and higher degrees, a standard requirement for entering the engineering profession. AI students were much more likely than non-AI students to report being underprepared for postsecondary educational pursuits, either academically or socially, and they were more likely to report financial concerns and to make negative statements about personal well-being and poverty, such as the many sub-themes under the heading of School Experience in response to Question 6. Twentythree percent of AI students reported math as a barrier to engineering, compared to 30 percent of non-AI students.

Generally speaking, the study indicated the importance of consistent attention to the following needs: 1) amelioration of poverty; 2) understanding of what engineering is and its tribal relevancy; 3) exposure to engineering with American Indian cultural emphasis in K-12 schools; 4) presence of role-model engineers in their daily lives; 5) encouragement and support from their peers, families, teachers, Elders, and tribal governments to value STEM education, particularly engineering fields; and (6) the embedded perceptions of math as a barrier to engineering studies.

\section{ACKNOWLEDGEMENTS}

This material is based upon work supported by the National Science Foundation (NSF) under Grant Number NSF 1037708. Any opinions, findings, and conclusions or recommendations expressed in this material are those of the authors and do not necessarily reflect the views of the NSF or of the colleges and universities with which the authors are affiliated.

We are indebted to OSSPEEC interns, including the following undergraduate students at SDSU who conducted interviews for this study: Wiyaka His Horse Is Thunder (also a co-author and now a graduate student), Stefanie Black Bear, Ashleigh Hare, Armando Hernandez, Ernest Weston, and Emily Meerdink. We thank Norm Braaten, Research Compliance Officer at SDSU, for consulting and for meeting with the project team regarding the ethical treatment of human subjects. Thanks to SDSU instructor Christina Geromatta, Assistant Professor Todd Letcher, and Professor George Hamer for helping to educate the project interns about the types of engineering, and to the SDSU Support Desk for technical assistance. 


\section{REFERENCES}

Aikenhead, G. (2001). Integrating Western and Aboriginal sciences: Cross-cultural science teaching. Research in Science Education, 31(3) 337-355. Retrieved from http://citeseerx.ist.psu.edu/viewdoc/summary?doi=10.1.1.511.7788.

American Indian Science and Engineering Society (AISES) (2015, Winter). Gathering together. Winds of change, 30(3), 2-7. Retrieved from http://www.nxtbook.com/nxtbooks/pohlyco/woc_2015winter/\#/10.

Annie E. Casey Foundation (2014). Race for results: Building a path to opportunity for all children. AECF: Baltimore, Maryland. Retrieved from http://www.aecf.org/m/resourcedoc/AECF-RaceforResults2014.pdf.

Aragon, S. (2002). An investigation of factors influencing classroom motivation for postsecondary American Indian/Alaska Native students. Journal of American Indian Education 41(1) 1-18. ERIC http://eric.ed.gov/?id=EJ652694.

Babco, E. (2005). The status of Native Americans in science and engineering. Washington, DC: Commission on Professionals in Science and Technology. Retrieved from http://ehrweb.aaas.org/mge/Reports/Report1/Babco-StatusOfNativeAmericansInSandE.pdf.

Baillie, C., Pawley, A., \& Riley, D. (2012). Engineering and social justice: In the university and beyond. West Lafayette, Indiana: Purdue University Press.

Barab, S.,Thomas, M., Dodge, T., Squire, K., \& Newell, M. (2004). Critical design ethnography: Designing for change. Anthropology \& Education Quarterly 35(2), 254-268.

Bernard, H. \& Gravlee, C. (Eds.). (2014). Handbook of methods in cultural anthropology. Lantham, Maryland: Rowman \& Littlefield.

Bosman, J. (2015, May 1). Pine Ridge Indian Reservation struggles with suicides among its young. The New York Times, p. A1. Retrieved from http://www.nytimes.com/2015/05/02/us/pine-ridge-indianreservation-struggles-with-suicides-among-young-people.html?_r=0.

Boyer, P. (n.d., ca. 2012). Bringing engineering to Native Americans: A status report on the National Science Foundation's Pre-Engineering Education Collaborative. Based upon work supported by NSF under grant no. HRD-1201657. Retrieved from http://www.swc.tc/scott\%20morgan/bringing_engeering_to_indians.pdf.

Boyer, P. (2015). Author archives: Paul Boyer. Native science report: STEM education at tribally controlled colleges. Sisseton Wahpeton College, TCUP, PEEC. Retrieved from http://online.swc.tc/peec/?author=2.

Cahalan, M. \& Perna, L. (2015). Indicators of higher education equity in the United States. Washington, DC: Pell Institute for the Study of Opportunity in Higher Education and Penn Ahead. VOCED, NCVER's International Tertiary Education, Research Database. Retrieved from http://hdl.voced.edu.au/10707/351467.

Carnevale, A. \& Strohl, J. (2010). How increasing college access is increasing inequality, and what to do about it. In R. Kahlenberg (Ed.), Rewarding strivers: Helping low-income students succeed in college (pp. 71-207). New York: Century Foundation Press.

Demmert, W., Grissmer, D., \& Towner, J. (2006). A review and analysis of the research on Native American students. Journal of American Indian Education 45(3), 5-23. Retrieved from http://citeseerx.ist.psu.edu/viewdoc/summary?doi=10.1.1.470.2213.

Chen, X. (July, 2009). Students who study science, technology, engineering, and mathematics in postsecondary education. National Center for Education Statistics, Washington, DC: US Department of Education. Retrieved from http://nces.ed.gov/pubsearch/pubsinfo.asp?pubid=2009161.

Dixon-Swift, V., James, E., Kippen, S., \& Liamputtong, P. (2007). Doing sensitive research: What challenges do qualitative researchers face? Qualitative Research 7(3), 327-353. DOI: 10.1177/1468794107078515.

Farnell, B. \& Graham, L. (2000). Discourse-centered methods. Bernard, H. (Ed.) In Handbook of methods in cultural anthropology. Lanham, Maryland: Altamira, 411-457.

Freire, P. (1970). Pedagogy of the oppressed. New York: Continuum.

Freire, P. (1976). Education: The practice of freedom. London: Writers and Readers Publishing Cooperative. 
Hammersley, M. \& Atkinson, P. (2007). Ethnography: Principles and practice, $3^{\text {rd }}$ Ed. London: Routledge.

Hansen, T. (2015, June). From space to Indigenous ancestral engineering: Commander John Herrington charts new territory. Indian Country Today Media Network.com. Retrieved from http://indiancountrytodaymedianetwork.com/2015/06/02/space-indigenous-ancestral-engineeringcommander-john-herrington-charts-new-territory?page=0\%2C0.

Howard-Brown, B. \& Martinez, D. (2012). Engaging diverse learners through the provisions of STEM education. Retrieved from http://secc.sedl.org/resources/briefs/diverse_learners_STEM/.

Kant, J., Burckhard, S., Kilts, W. \& Min, K. (2014a). Increasing diversity in engineering: Capacity building matters. Proceedings of the ASEE North Midwest Section Conference, Iowa City, Iowa, October 17, 2014. http://ir.uiowa.edu/aseenmw2014/diversity/2A/1/.

Kant, J., Tinant, C., Burckhard, S., \& Sawyer, J. (2014b). Partnering with a Native American community in a collaboration between a tribal college and two mainstream universities. In University engineering programs that impact communities: Critical analyses and reflections (Special Edition). International Journal for Service Learning in Engineering (IJSLE), Special Edition, Fall, pp. 460-474. http://library.queensu.ca/ojs/index.php/ijsle/article/view/5563/5330. ISSN 1555-9033.

Kant, J., Larson, G., Burckhard, S., Berdanier, B., \& Meyers, R. (2015, Spring). Contemporary use of wild fruits by the Lakota in South Dakota and implications for cultural identity. Great Plains Research, 25(1), 13-24.

Kristof, N. (2012, May 9). Poverty's poster child. The New York Times. Retrieved from http://www.nytimes.com/2012/05/10/opinion/kristof-povertys-poster-child.html?_r=0.

Liamputtong, P. (2007). Researching the vulnerable: A guide to sensitive research methods. London: Sage Publications. DOI: $10.4135 / 9781849209861$.

Liamputtong, P. \& Ezzy, D. (2005). Making sense of qualitative data: Analysis process. In Liamputtong, P. \& Ezzy, D. (Eds.) Qualitative Research Methods, 2nd Edition, South Melbourne: Oxford University Press, 257285.

Maslow, A. (1943). A theory of human motivation. Psychological Review 50(4), 370-96. ISSN 1492-3713. Retrieved from http://psychclassics.yorku.ca/Maslow/motivation.htm.

National Center for Educational Statistics, U. S. Department of Education (2008). Status and trends in the education of American Indians and Alaska Natives: 2008. Retrieved from http://nces.ed.gov/pubs2008/nativetrends/index.asp.

National Center for Educational Statistics (2011). National assessment of educational progress. National Indian education study. Retrieved from https://nces.ed.gov/nationsreportcard/nies/nies_2011/national_sum.aspx.

National Institutes of Health (2015). Protecting human subjects in research. Retrieved from https://phrp.nihtraining.com/users/login.php.

National Science Foundation (2011). Women, minorities, and persons with disabilities in science and engineering. Data tab, tables. Table 2-10. Undergraduate enrollment in engineering programs, by sex, enrollment status, race or ethnicity, and citizenship: 2011. Retrieved from http://www.nsf.gov/statistics/2015/nsf15311/tables.cfm\#http://www.nsf.gov/statistics/2015/nsf153 11/tables/pdf/tab2-10.pdf.

Norris, T., Vines, P., \& Hoeffel, E. (2012, January). The American Indian and Alaska Native census population: 2010. 2010 Census briefs, C2010BR-10. US Census Bureau: US Department of Commerce, Economics and Statistics Administration. Retrieved from http://www.census.gov/prod/cen2010/briefs/c2010br-10.pdf.

Pewewardy, C. (2002). Learning styles of American Indian/Alaska Native students: A review of the literature and implications for practice. Journal of American Indian Education 41(3), 22-56. Retrieved from http://my.tru.ca/_shared/assets/Pewewardy_2002_Learning_styles_Aboriginal23616.pdf.

Savin-Baden, M. \& Howell Major, C. (2013). Qualitative research: The essential guide to theory and practice. New York: Routledge.

Small, M., Harding, D., \& Lamont, M. (2010, May). Reconsidering culture and poverty. The Annals of the American Academy of Political and Social Science 629, 6-27. DOI: 10.1177/0002716210362077. 
Sawyer, J., Kant, J., Benning, J., Fick, D., \& Burckhard, S. (2014). Forging partnerships, experiential learning, and community impact: Capacity building matters. Proceedings of the ASEE North Midwest Section Conference, Iowa City, Iowa, October 17, 2014. http://ir.uiowa.edu/aseenmw2014/diversity/2A/2/.

Straits, K., Bird, D., Tsinajinnie, E., Espinoza, J., Goodkind, J., Spencer, O. Tafoya, N., Willging, C., \& The guiding principles workgroup (2002). Guiding principles for engaging in research with Native American communities, Version 1. University of New Mexico Center for Rural and Community Behavioral Health \& Albuquerque Area Southwest Tribal Epidemiology Center. Retrieved from http://www.aastec.net/wpcontent/uploads/2012/11/Guiding_Principles_v1.pdf.

Strauss, A. \& Corbin, J. (1990). Basics of qualitative research: Grounded theory procedures and techniques. London: Sage.

Tinant, C., Kant, J., LaGarry, H., Sanovia, J., and Burckhard, S. (2014). Building trust, experiential learning, and the importance of sovereignty: Capacity building in pre-engineering education - a tribal college perspective. Proceedings of the ASEE North Midwest Section Conference, Iowa City, Iowa, October 17, 2014. http://ir.uiowa.edu/cgi/viewcontent.cgi?article=1016\&context=aseenmw2014.

US Census Bureau (2013a). American fact finder. Selected population profile in the United States, 2013 American Community Survey 1- Year Estimates (S0201). American Indian and Alaska Native alone or in combination with one or more other races (300, A01-Z99) \& (100-299) or (300, A01-Z99) or (400-999).

US Census Bureau (2013b, December). American Indian and Alaska Native tribes in the United States and Puerto Rico: 2010 (CPH-T-6). Table 56. American Indian and Alaska Native Population by Tribe for South Dakota: 2010, CPH-T-6. US Department of Commerce, Economics and Statistics Administration. Retrieved from http://www.census.gov/population/www/cen2010/cph-t/cph-t-6.html.

Young, S. (2008, September 20). Why are young Lakota killing themselves? South Dakota reservation's suicide rate said to be among highest in world. Argus Leader Newspaper, Sioux Falls, South Dakota, n.p. Retrieved from http://archive.argusleader.com/article/20080921/RESERVATIONSUICIDE/309210003/Whyyoung-Lakota-killing-themselves-. 